\title{
Post Break-up Housing Pathways of Young Adults in England in Light of Family and Friendship-based Support
}

DOI:

10.1080/13676261.2019.1679358

\section{Document Version}

Accepted author manuscript

Link to publication record in Manchester Research Explorer

\section{Citation for published version (APA):}

Aeby, G., \& Heath, S. (2019). Post Break-up Housing Pathways of Young Adults in England in Light of Family and Friendship-based Support. Journal of Youth Studies. https://doi.org/10.1080/13676261.2019.1679358

\section{Published in:}

Journal of Youth Studies

\section{Citing this paper}

Please note that where the full-text provided on Manchester Research Explorer is the Author Accepted Manuscript or Proof version this may differ from the final Published version. If citing, it is advised that you check and use the publisher's definitive version.

\section{General rights}

Copyright and moral rights for the publications made accessible in the Research Explorer are retained by the authors and/or other copyright owners and it is a condition of accessing publications that users recognise and abide by the legal requirements associated with these rights.

\section{Takedown policy}

If you believe that this document breaches copyright please refer to the University of Manchester's Takedown Procedures [http://man.ac.uk/04Y6Bo] or contact uml.scholarlycommunications@manchester.ac.uk providing relevant details, so we can investigate your claim.

\section{OPEN ACCESS}




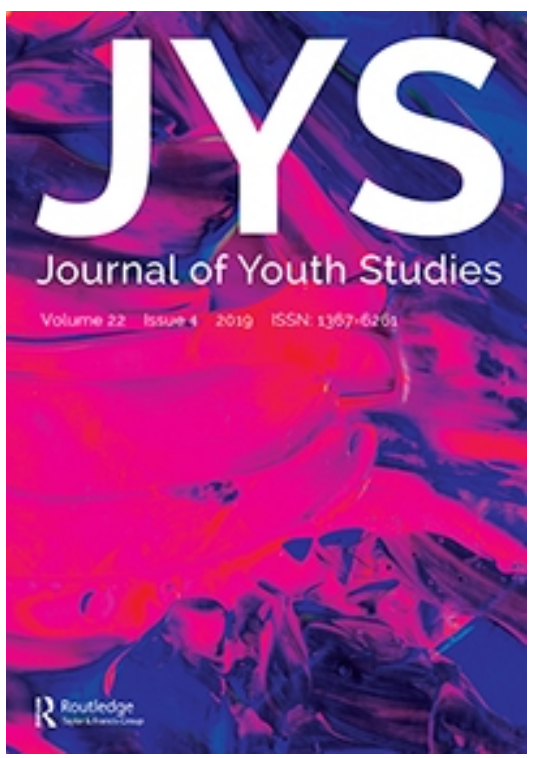

Post Break-up Housing Pathways of Young Adults in England in Light of Family and Friendship-based Support

\begin{tabular}{|r|l|}
\hline Journal: & Journal of Youth Studies \\
\hline Manuscript ID & CJYS-2018-0245.R2 \\
\hline Manuscript Type: & Article \\
\hline Keywords: & $\begin{array}{l}\text { housing choice, intimate relationship breakdown, Young adulthood, } \\
\text { support, residential mobility }\end{array}$ \\
\hline
\end{tabular}

\section{SCHOLARONE \\ Manuscripts}




\section{Post Break-up Housing Pathways of Young Adults in England in Light of Family and Friendship-based Support}

This paper explores the housing pathways of young adults following the breakdown of a first intimate relationship based on co-residence. In particular it explores the frequent recourse to shared housing and returns to the parental home, and how these options may be seen as steps backward, yet also offer opportunities for support. Findings are discussed in the context of the de-standardisation of transitions to adulthood characterized by uncertainties related to early years of employment and the shortage of affordable housing. Although often not as consequential as mid-life relationship breakdowns for future housing prospects, intimate relationship breakdowns linked to initial co-residence are nonetheless critical life events for young adults, leading to a reevaluation of their existing relationships and of their plans in relation to housing and family formation. Our findings also indicate that the backwards and forwards movements associated with intermediary housing arrangements and in-between phases are deserving of greater attention.

Keywords: housing choice, intimate relationship breakdown, young adulthood, support, residential mobility 


\section{Introduction}

In young adulthood, first experiences of living with a partner are frequently imbued with hopes for a common future, but are also constrained by uncertainties related to the early years of employment and the ability to access affordable housing. The subsequent breakdown of a first co-resident relationship is, then, arguably a critical life event for young adults, as it invariably leads to new housing arrangements for at least one member of the couple. Whilst the consequences of intimate relationship breakdown in mid-life have received considerable attention (Amato 2010; Beer and Faulkner 2011), the specific challenges facing younger adults are relatively neglected, despite the delaying effect that their changed housing circumstances can have on other life transitions.

This paper illuminates this issue through focusing on the post-breakdown housing pathways of a sample of young adults without children living in England. It sheds light on how they cope with a first major intimate relationship breakdown based on co-residence largely in the form of cohabitation but in a small number of cases shifting to marriage following initial cohabitation. It focuses in particular on pathways back into house sharing and the parental home, options which, despite their initial lack of appeal to those used to living independently as part of a couple, frequently provide short- and medium term solutions for young adults who find themselves single again. Although both possibilities are often perceived as backward steps, they may also turn into opportunities to receive support and to consolidate both new and existing relationships. First, we contextualise the negotiation of housing pathways and couple formation for young adults, highlighting the greater diversity of living arrangements experienced by young adults in the United Kingdom and in other Western countries; the significance attached to cohabitation and home ownership; the prevalence of shared housing; and the incidence of returning to the parental home.

\section{Negotiating Housing and Couple Formation in Young Adulthood}

It is widely accepted that transitions to adulthood in Western Europe have been extended and diversified in recent decades (Furlong and Cartmel 2006; Antonucci, Hamilton, and Roberts 2014), marked by a postponement of traditional transition markers and greater age variation in transition event timing (Buchmann and Kriesi 2011). These are related to wider processes of de-standardization and differentiation (Brückner and Mayer 2005). While transitions to adulthood used to coincide with employment market entry, leaving the parental home, and 
partnering, these events have become de-synchronized, and reversible (e.g., return to the parental home), resulting in a de-coupling of events between the school-training-work nexus and family formation (Brückner and Mayer 2005). Thus while the transition to adulthood conventionally starts around 18 years old, its end point is less clear as it is still strongly related to settling into work and family roles which, for many, does not happen until well into their 30s (Arnett 2014; Wong 2018).

In the UK as in other Western countries, the last four decades have seen a marked decline in marriage rates amongst younger cohorts, a rise in the mean age of first marriage and parenthood, a growth in solo and shared living arrangements, and an increased incidence of young adults staying in, and on leaving subsequently returning to, the parental home (Bynner 2011; Furlong 2016). In addition, intimate relationship breakdowns are a common experience, with 101,669 divorces of opposite-sex couples in England and Wales in 2017 and an estimated 42 percent of marriages ending in divorce (ONS 2018a), and even higher dissolution rate for cohabiting couples (Beaujouan and Ní Bhrolcháin 2011). Yet couple relationships remain widely aspired to by young people, even as they are more difficult to achieve and sustain in the context of residential independence. In the American context for instance, Arnett (2016) found that the majority of young people across all social backgrounds aspire to lasting commitments (including marriage and childbearing within wedlock), which prompts Silva (2016) to expose a two-tiered family system in which actual achievement of lasting commitment remains elusive for many working-class young Americans.

With the gradual rise in the mean age of marriage and parenthood, first cohabitation has in itself become a significant relationship milestone and, is frequently a 'first step' towards these other statuses (Berrington, Perelli-Harris, and Trevena 2015). Nevertheless, cohabitation is no guarantee of lasting commitment, with first cohabitations in particular more likely to be temporary and experimental rather than leading to marriage (Furlong and Cartmel 2006). Cohabitation has then become an additional non-stable relational pattern for many young adults (Manning and Schmock 2005), not necessarily representing a long-term commitment but simply a way to be together 'for now'. Despite this, first experiences of cohabitation are still frequently imbued with hopes and expectations for a common future, whether as an alternative or a precursor to marriage (Beaujouan and Ní Bhrolcháin 2011; Perelli-Harris et al. 2014). In 2017, for example, half of all children born in England were born outside wedlock (ONS 2018b) which shows that both cohabitation and marriage can 
lead to long-term commitments. To sum up, in either case, cohabitation is perceived as a step forward from the perspective of a life-course project and a couple will often mark this moment by moving into a property which is new to both of them.

Whilst renting a property together is in itself a significant legal and financial commitment, in countries such as the UK which place strong ideological emphasis on the desirability of home ownership, buying a property together often takes on even greater significance as a marker of commitment. Using focus groups to discuss the perceived differences between cohabitation and marriage amongst 25 to 40 year olds in different European countries, Perelli-Harris et al. (2014) found that a joint mortgage and children were regarded as greater signs of couple commitment in the UK than marriage, despite increasing difficulties of securing owner occupation. Although the UK rate of ownership is still quite high (63 per cent in 2016/17), there has been a significant decrease in recent years amongst younger adults in particular due to the effects of the housing bubble and the aftermath of the 2008 economic crisis (Bone and O'Reilly 2010). For example, despite 81 per cent of 25 to 34 year olds expressing a preference for owner occupation within a two year window (Panell 2016), only 37 per cent of this age group actually achieved this in 2016/17, compared with 57 per cent just ten years earlier (MHCLG, 2018). Given the difficulties of acquiring a mortgage on a single income, saving for a joint mortgage with a partner is for many the only way of accessing owner occupation, especially for those unable to obtain financial support from relatives [author $(s)]$. Under these conditions, relationship breakdowns take on particular significance and are likely to have negative effects on subsequent housing options, including through forcing a return to living arrangements which a young person may have thought were behind them, such as living in shared housing or returning to the parental home.

When considering early housing pathways in the UK, it is also important to place them within a broader European context. Arundel and Ronald (2016) found high variation amongst 18 to 34 year olds from across fourteen European countries in terms of whether they had established an independent household (between circa $80 \%$ in social democratic welfare states to below $40 \%$ in Mediterranean welfare states), or were living in semi-dependent housing, either in parental co-residence (between almost 60\% in Mediterranean welfare states to below $20 \%$ in social democratic welfare states), or shared living arrangements (between $10 \%$ to $1 \%$ ) In this context, and in common with conservative welfare states, the liberal UK lies between these extremes, with 50 per cent living in independent households 
and $40 \%$ living with parents, but stands out for its high rates of shared living. Indeed, the prevalence of shared living arrangements after first leaving the parental home and prior to forming a couple household is a particularly distinctive feature of UK housing pathways, with approximately 10 per cent of 18 to 34 year-olds in this situation (ibid). In the UK, there is also a normative push to leave the parental home early, despite low levels of job security and minimal public assistance to sustain this departure (ibid). The assumed responsibility for supporting adult children mostly falls on parents' shoulders until a young person turns 25 (Furlong and Cartmel 2006). Sharing with peers provides a solution to this source of tension, offering cheaper and flexible housing solutions, in contrast to social democratic welfare states where state support is greater and where living alone is more common for early leavers from the parental home (Stephens and Blenkinsopp 2015), and in Mediterranean welfare states where parental co-residence for young adults is well accepted ([author(s)]; Arundel and Ronald 2016). Nevertheless, renting or buying on one's own or with a partner remains a common goal for those who can afford it, such that a return to the shared housing sector may be perceived as a retrograde step.

Regarding more specifically the departure from the parental home, there is intracountry variation depending on social class, gender, and family structure. Middle class young people tend to experience "living away" from the parental home - leaving earlier but returning after graduation - in contrast to their working class peers who tend to stay longer and then leave for good; women tend to leave earlier than men (also associated with a younger age at first marriage and childbirth); and, those living in divorced families tend to leave earlier than peers from two parent families ([author(s)]; Furlong and Cartmel 2006; Jones 1995). The incidence of returning to the parental home after having first departed has also increased in recent years for certain groups, notably young women in their early twenties, especially when they first graduate (Stone, Berrington, and Falkingham 2014; Roberts et al. 2016). However, returns are also triggered by events such as unemployment or relationship breakdown (Stone, Berrington, and Falkingham 2014). In such cases, the likelihood to opt for a return is also based on the availability of other resources. Berngruber (2015) has shown in the German context, for example, that the more financially and socially independent young adults are, the less likely they are to move back in with their parents. In addition, giving financial support rather than living space to adult children is more common in northern European countries than in southern European countries (Isengard, König, and 
Szydlik 2017). Overall, no matter the specific circumstances, returns to the parental home are generally viewed ambivalently by both young adults and their parents, and most hope for a swift exit at the earliest opportunity (Lewis et al. 2016).

Overall, then, young adults are taking longer to "settle down" than earlier cohorts, reflected in the greater diversity of living arrangements experienced by this group in many European countries (Forrest and Yip 2013). Yet, whilst much attention has been aimed at understanding the unfolding of employment and family trajectories, until recently housing trajectories have been relatively neglected despite being strongly interlinked with these two others (Arundel and Ronald 2016). For example, partnership formation and childbirth often precipitate housing moves whilst, conversely, housing circumstances often influence domestic transitions, such as the timing and desirability of cohabitation, marriage and parenthood (Bone and O'Reilly 2010; Mulder 2007; Berrington and Stone 2014). Intimate trajectories prior to family formation also tend to be neglected, even though they are both quantitatively important, as young adults often engage in relationships varying in duration and degree of commitment, and qualitatively important, as emerging adulthood is a key stage in learning how to coordinate couple commitment with individual life plans (Tuval Mashiach, Hanson, and Shulman 2016; Shulman and Connolly 2013). Existing cultural scripts also tend to present life as a linear progression into the future (Phoenix and Sparkes 2008), according to which individuals measure their own lives as either 'on time,' 'early' or 'late' (Neugarten, Moore, and Lowe 1965), despite greater uncertainty in transitional processes. Nonetheless, as they approach 30, increasing numbers of young adults tend to make the transition to longer and more stable relationships (Cohen et al. 2003), but these are still subject to instabilities and the risk of a break-up, diverting them from 'on-time' transitions.

This overview leads us to the question of the impact of intimate relationship breakdowns on the housing trajectories of young adults without children in England. Drawing on qualitative data from interviews with 29 young adults who had all experienced the breakdown of a first co-resident relationship (largely in the form of continuous cohabitation but in a small number of cases shifting at some point into marriage), in what follows we will briefly consider their routes into co-residence and then explore their immediate and mid-term postseparation housing strategies, focusing on two pathways in particular which may at least initially be perceived as 'backward' steps: returns to the parental home and recourse to shared housing. First, we introduce the studies upon which we draw in exploring these issues. 


\section{Researching Young Adults' Post Break-up Housing Pathways}

This paper combines data from two complementary studies, both of which included a focus on post-separation housing pathways as part of a broader exploration of the intersections between housing and relationship trajectories. The first study focused on the consequences of intimate relationship breakdown amongst adults living in Northern England and Switzerland with a focus on personal networks ${ }^{1}$, and was based on qualitative interviews with 30 participants, whilst the second study focused on the housing pathways of single young adults living on the English south coast with a focus on inter- and intra- generational transfers ${ }^{2}$ and was based on qualitative interviews with 37 participants. Critically, similar questions about the linkages between housing and relationship trajectories were asked of participants in both studies, with the two data sets comparable in their coverage in relation to the issues explored in this paper. More specifically, in both studies, participants' housing pathways were fully reconstructed, and put in perspective with other life trajectories, including in relation to support and hindrance arising from family and personal relationships. Across the two studies, then, rich data were generated about moves back and forth linked to changing relationship statuses, and the consequences of these movements. In both studies, participants were recruited through advertisements and snowball sampling, with interviews largely conducted in public cafes and bars. All were fully transcribed, and then analysed thematically using qualitative software as a coding tool.

For the purposes of this paper, we constructed a combined sample of UK-based participants without children who had all experienced an intimate relationship breakdown involving a partner with whom they had formerly resided. Our principal rationale for combining data from these two studies was to generate a sample of young adults which had greater variability than was possible by focusing on either study in isolation rather than to facilitate a comparative analysis between the two sub-samples. Nonetheless, there are a few small differences in the composition of the two sub-samples, which we outline below.

The combined sample comprises 29 young adults in their mid-20s to mid-30s: 15 from Northern England (eleven women and four men) and 14 from Southern England (ten

1 This first study (TITLE) was conducted between 2016 and 2017 and was funded by (granted to : Grant Reference Number:

2 This second study (TITLE) was conducted in 2010 and was funded by Number ). Thanks are due to for conducting the interviews. (Grant Reference 
women and four men) (see Table 1 below). We opt for this rather wide age window, as 'emerging adulthood' can now extend well into the 30s (Arnett 2014; Wong 2018). Most had grown up in the UK and most were white British. The mean age within both sub-samples was 30 at the time of interview, although the period of co-residence and subsequent relationship breakdown had in many cases happened several years earlier. Periods of co-residence had lasted between seven months and ten years, and for most it had been their first and only experience of living with a partner. Eight people had married their partner during this period of first co-residence, whilst two had become engaged to them. Critically, though, their spouse had been the only partner they had lived with prior to converting their cohabitation into marriage. Four had been in a same-sex partnership. None of the 29 participants were former partners of any of the other participants. Despite the gender imbalance, we felt it important to retain the eight young men within our analysis, and both men and women faced very similar difficulties and dilemmas. This would probably not have been the case if our participants had been parents, as the presence of children renders young women particularly vulnerable following a separation (Hilton \& Anderson 2009), but this was not our focus.

\section{[Table 1 about here]}

Finally, the sample is relatively highly educated, with non-graduates proving harder to recruit via the convenience sampling methods used in both studies, despite attempts to broaden the base of both samples. All of the northern participants and 11 of the southern participants had experience of higher education (HE), with all but two having gained at least a bachelor's degree, one in the middle of her degree, and the other having dropped out before completion. Whereas all but one of the northern sample had attended university almost straight from school, only six of the 11 southern participants with experience of HE had done so, with one taking a gap year and a further four returning to study as mature students. The housing pathways of southern participants are consequently more diverse than amongst the northern sample, including when first leaving the parental home. To some degree this point of difference also stands as a proxy for differences in socio-economic background, with the nongraduates and mature students tending to come from slightly less economically advantaged backgrounds than those who proceeded straight into HE from school. To sum up, despite limitations on our ability to systematically test social class, our qualitative approach nonetheless pinpoints some possible differences and, more importantly, tackles the complex back and forth moves linked to changing relationship statuses. 


\section{Post Break-up Housing Pathways}

In the following sections, we firstly outline the pathways into initial co-residence of our 29 participants, before briefly summarising their immediate post-breakdown housing options. We then consider their pathways after this initial period of 'emergency' adjustment, organised around two main 'backward' steps: returns to the parental home and entering shared living arrangements.

\section{Moving in Together: a Step Forward}

For all but four participants, the period of co-residence and subsequent break-up which they told us about had been their first such experience, with the remaining four for various reasons regarding their first cohabitation as 'not properly counting'. Most had nurtured high expectations and hopes for their relationship, with cohabitation perceived as a significant step forward as a couple. For half, this had involved finding a property that was new to both of them, and often in a location that was also new to both. The other half had either moved into their partner's house (ten cases) or their partner had moved in with them (five cases), in three cases into a house which their partner already owned, with all three feeling some degree of uneasiness about this. Six others bought a house together with their partner after initially renting, while the remaining couples remained in rental properties throughout their time together.

Most participants considered their initial decision to cohabit in terms of a positive couple project. For example, Emily highlighted a qualitative difference between her relationship with her co-resident partner, Jason, and with the boyfriend she had casually dated at university: 'But with Jason like I had thought I had found the guy I was going to marry. I was head over heels in love with him, so when we broke up it absolutely broke my heart.' This embracing of a couple project was evident even when wider circumstances had acted as a catalyst for moving in together: Camila, for example, had left her parental home to simultaneously begin a Master degree and to start cohabitating with her partner in a new city. One third had taken a further step of marriage or engagement, highlighting how cohabitation remains a precursor to marriage for some young adults (Perelli-Harris et al. 2014) despite generally declining marriage rates amongst younger cohorts. Nine participants also had achieved home ownership, a culturally desirable status (Panell 2016) implying a high level of 
commitment. However, in some cases the overriding motivation for cohabitation was pragmatic, for example following serious illness or other options having fallen through. Cohabitation is then often perceived as a first step towards other statuses (Berrington, PerelliHarris, and Travena 2015), but can also be a pragmatic, temporary solution for young people in housing need (Manning and Schmock 2005).

All of these relationships had eventually ended, largely due to changed feelings about each other, but sometimes exacerbated or hastened by wider circumstances, such as one partner needing to relocate for work or no longer being able to pay their way due to reduced income, confirming the temporary and experimental nature of many first-time cohabitations (Furlong and Cartmel 2006). Individual life plans often took priority and compromised couple commitment, a not uncommon situation during emerging adulthood (Shulman and Connolly 2013). Some of these relationships had also turned out to be abusive in various ways, especially those marked by relatively early partnership formation, where poor money management and debt had also contributed to the relationship's demise. Nonetheless, regardless of who was at fault or the specific reasons for the break-up, the relationship's end was generally perceived as a failure, even when it came as a relief, and immediately presented a very practical challenge: where to live now?

Immediate responses to this challenge were as follows: temporarily continuing to live with their ex-partner in the absence of other immediate options, seeking temporary refuge with friends, remaining in the house they had shared whilst their partner moved out, moving in with parents, and moving straight into other tenancy arrangements, sometimes alone but more often in shared private rentals. Moving in with parents and into house shares also featured as common longer term strategies for participants after the immediate crisis, despite the sense that they both represented a backward step after having lived independently with a partner, and it is these two options which we now consider in greater detail.

\section{Returning to the Parental Home: a Step Back?}

First, we consider how our participants felt about the prospect of returning to the parental home following their break-up. In line with other studies showing that returning to the parental home after first having left has become an increasingly common phenomenon (Stone, Berrington, and Falkingham 2014), eleven already had prior experience of returning to the parental home after first having left, in all but two cases after first graduating, and for 
periods ranging from a few months to five years. Seven had returned home immediately after their break-up, including three for whom it was their first return, whilst in some cases this became a longer-term solution, as we explain below.

Returning to the parental home took on particular significance for those who had experienced abusive relationships and/or particularly traumatic break-ups, suggesting that they were seeking more than just physical shelter in the immediate aftermath of their separation and that, to them, the parental home was a place of sanctuary and protection. Emily, for example, experienced it as a recovery retreat ('I had to just get myself back together'), whilst Adam described moving in with his mother as 'the easiest option' and 'a safe bolthole'. Others had significant debts following the break-up, such that the parental home was the only realistic alternative available to them.

Nonetheless, for most participant, returning to live with parents came at a high personal price. For example, at least two participants had to change job due to the considerable distance between the parental home and their former place of residence. In such cases, a return home in conjunction with a break-up marked a major disruption to the direction of their lives, often accompanied by varying degrees of mental distress. Judith, for example, spoke of the necessity of moving home just to kind of get my head back together and get myself back on my feet...' Likewise Adam, whilst glad to move back at one level, also described how it had 'felt like a backwards step, because you know you sort of go out in the world and do stuff and then I have to come back to my mum.' Despite these misgivings, he had ended up staying for two years. This points to the ways in which parent and adult child relationships are imbued with intergenerational ambivalences due to the tension between dependence and autonomy (Lewis et al. 2016). Nonetheless, for those who decided to return, the benefits tended to outweigh the costs of dependence, despite reinforcing feelings of ambivalence. Further, these periods of return could provide opportunities to renegotiate the parent-child relationship. Katy's mother had herself recently undergone a relationship breakdown and she and Katy were able to bond over this experience. Likewise, Judith spoke of how she and her parents, after a difficult start, had come to a new appreciation of each other, to the point that 'I absolutely loved being back home. Yeah, it was really good. Because they'd become, I think because I'd grown up a bit more, they were more like my friends as well as my parents, but generally I get on with them like as a friend more than anything, so yeah, no it was really good.' 
Nonetheless, the majority of participants avoided returning to the parental home. Several participants spoke of how an inevitable loss of freedom meant that they had declined their parents' offers of temporary accommodation, often using geographical distance as the pretext not to return. Melissa's parents, for example, had wanted her to return to their home in northern England, but she feared that if she had done so she would probably never have returned to her life in the south. Toby had likewise resisted the temptation to return to his parents: 'I suppose mentally maybe kind of just running home isn't really what I want to do... I want to be maybe more like no, I can look after myself, rather than just going oh it's all falling to pieces, I'll go home, run home, run to my parents' home.'

Finally, two participants, whilst not returning to their parental home, were helped by their parents to remain on the housing ladder through direct financial assistance for owner occupation, something they would not have managed on their single income. In addition, participants frequently reported being able to count on help from their family of origin during the relationship breakdown, whether advice, emotional support, financial help or other practical matters. These examples show how both financial support and provision of a living space may be given in the case of an intimate relationship breakdown, highlighting the persistent importance of parents not only to assist the transition to adulthood, but also to buffer the consequences of critical life events leading to temporary vulnerability. This is especially important in countries like the UK which lack a welfare regime with strong policies sustaining individuals' independence (Arundel and Ronald 2016).

\section{House Sharing: a Step Backward but a Move forward toward Friendship}

We now consider how house sharing featured in the housing strategies of participants. Four had sought immediate temporary refuge by sharing with friends. Andrew, for example, moved in with a friend for a few months, and the kindness of the housing offer coupled with a readiness to talk endlessly about the situation subsequently made this person central to Andrew's life. Melissa also relied on the generosity of a relatively new friend; after an aborted attempt by Melissa to move overseas after her break-up, culminating in homelessness and briefly having to live out of her car, the friend had offered Melissa his spare room for six weeks. No other friends had offered to help her out and this person had continued to be an important friend to her subsequently. 
A settled tenancy in shared housing had been an immediate post-split option in only three cases, presumably because most shared tenancies involve an initial six month contract when most were seeking only a temporary solution to their immediate housing need and hoped for a better solution. Nonetheless, as a medium- to longer-term strategy it was pursued by a sizable proportion of the sample, with twelve participants living in shared housing at the time of the interview and a further six having experienced it at some point following their break-up. More than two thirds had shared at least once prior to cohabitation, and none had expected to do so again after having moved in with a partner. Consequently, returning to shared housing was largely perceived as a step backward, especially by those who had previously shared extensively. Mary, for example, had lived with an old school friend for two years after her break-up before renting a flat on her own, but they did not always get on due to conflicting expectations of the degree to which they would socialise together. Teresa also spoke of how she had initially shared with an older, long established tenant who behaved as if she was the resident landlady, and this had not been a happy time for her.

Despite the negative feelings associated by many participants with the experience of house sharing after having cohabited with a partner, in many cases housemates had nonetheless proved to be very good sources of support. Due to their work commitments, participants often had less time and energy to develop new friendships, and immediately after a break-up were often even less inclined to socialise. Housemates could, then, become central to each other's' sociability practices, providing a 'ready-made social life' and opportunities to access the friendship networks of housemates by virtue of physical proximity, as previous research has found [author(s)]. This potential for accessing new friendship networks through sharing with others is particularly important, as friendships are often tested during critical life events such as a break-up because individuals are in need of intense emotional support ([author(s)]; Rubughini 2011). Some friendships, especially those involving the mutual friends of a couple, do not survive the end of the couple relationship, which creates a greater need for new supportive relationships (Kalmijn and Broese van Groenou 2005; Terhell, Broese van Groenou, and van Tilburg 2007). Sharers all agreed that living alone was not the best arrangement in a time of emotional frailty. In contrast, living together meant sharing intimacy, whether when eating together, watching TV, or the everyday ups and downs of house sharing. Housemates were also functionally dependent on each other with regard to household tasks and utility bills, aspects of household organisation which can often lead to 
tensions and conflicts, but also to practices of care and exchanges of emotional support. The negative symbolic meaning of re-entering house sharing was, then, ameliorated for many by the positive experience of having housemates who became friends. Participants also noted that house sharing after cohabitation did not mean returning to student housing conditions, but living in 'nice' places, with housemates already integrated into the employment market.

Amongst those who had never previously shared, there was, for some, something of a novelty value about adopting a living arrangement which felt they had missed out on or were unlikely to ever experience. Nonetheless, for more experienced sharers the ability to move fairly quickly into a situation where they could live alone had been important, despite appreciating the temporary benefits of house sharing. Adam, for example, had lived in multiple house shares, always with strangers, and as part of a fairly transitory housing history more generally which had also led him back into the parental home as an immediate response. Being able finally to live alone was, he declared 'wonderful. I'm fed up of living with other people'.

Finally, for the seven participants who had bought a house with their then partner or who, like Henry, had bought a share in his then partner's house, the feeling of a backwards movement was even stronger, and it was striking that in most cases this group had managed to avoid moving back into house shares despite having to sell up in some cases. Of the seven participants who had become homeowners during their cohabitation, three fell out of home ownership following their break-up. The exception was Henry who, after a year in a shared rental, had bought his own house and became a live-in landlord. All of his lodgers had become significant people in his life, highlighting how sharing was important to him for friendship. Being a live-in landlord gave him the prestige of ownership and the advantages of a reservoir of potential friends.

To summarise, we have analysed the immediate to mid-term post-separation housing strategies of our participants. After a period of transition and change, most had settled into more permanent arrangements. At the time of interview, 14 were living on their own (three with mortgages) underlining the high value associated with independence when in more stable conditions, emotionally and materially; 12 were living in shared housing (one as a livein owner); one had moved back into her parental home; and two were cohabiting with new partners. In addition, 14 participants had new non-resident partners, with five hoping to 
cohabit in the short to medium term. It seemed that the hopes and expectations for a common future that had imbued the initial experiences of cohabitation amongst this group had been transferred to their new intimate relationships.

\section{Discussion}

First-time cohabitations are often perceived as a step forward towards other statuses and family formation (Berrington, Perelli-Harris, and Travena 2015), but some can also provide a pragmatic, non-committed housing solution (Manning and Schmock 2005). They also tend to be more unstable than subsequent periods of cohabitation, with young adults learning how to balance individual and couple projects (Tuval Mashiach, Hanson, and Shulman 2016; Shulman and Connolly 2013). In our sample, the majority of the young adults entered coresidence with enthusiasm as part of a couple project and a sizable number had already gone a step further with marriage and/or home ownership.

An intimate relationship breakdown is a critical life event no matter when it happens during the life course. It invariably leads to new housing arrangements, with consequences for future housing pathways and potential risk of delay in the timing of other life transitions, and we found this to be equally the case for young childless adults experiencing the end of their first period of co-residence. Indeed, living with a partner meant that their rent and living costs were shared and, in the context of a competitive employment market and the UK's housing crisis (Bone and Reilly 2010), economic constraints weighed very heavily on their housing decisions after the relationship breakdown. In several cases, the break-up preceded the end of a rental contract, so decisions also had to be made about how to cover the remaining costs if, as usually happened, one of the partners moved out. In addition, nearly all of the 29 participants experienced some degree of strain arising from being in the early stages of their careers, which often conflicted with their couple project. In other cases, the pressing need to return to the parental home, for various reasons an increasingly common phenomenon (Stone, Berrington, and Falkingham 2014), despite it being at some geographical distance from where the couple had resided, meant that their employment trajectories were set off course by having to leave existing jobs and finding work in the locality of their parental home.

These young adults first had to come up with short-term housing solutions and then find solutions that would work for the longer term. In this regard, shared housing proved to 
be the best option for many, at least in the mid-term, allowing them to remain relatively independent. In contrast, returning to the parental home also gave rise to intergenerational ambivalences (Lewis et al. 2016), despite it sometimes being seen as a temporary healing retreat, which explains why most participants preferred avoiding this solution. House sharing - initially seen as a step backward, albeit preferable to living with parents - often proved in time to be a very positive experience, even if many eventually tired of it. It could provide a 'ready-made social life' [author(s)], and a place to recover from the relationship breakdown. Therefore, in addition to being a good solution for mobile young professionals, house sharing also has advantages for individuals experiencing a critical life event like an intimate relationship breakdown. Nevertheless, living in a house share may also hinder the development of new couple relationships, because of a lack of personal space and privacy [author(s)]. In that context, living alone seems to be a preferred solution which creates fewer conflicted feelings, and a greater sense of control and freedom. This option was by no means wished for by everyone, and also was not economically viable for everyone.

As to their futures, in the long-term almost all participants hoped to live with a partner again, but they did not feel the need to rush into this, and were more pragmatic regarding the risks and the flaws. The idea of a housing ladder marked by eventual owner occupation (Panell 2016) remained a defining feature of most participants' plans, as did the desire to find the 'right' partner (often with plans for family formation), but having experienced a step backward in both their household and housing trajectories as a consequence of their break-up, most contested the idea of a 'right' timing (before 30, for example) and found meaning in enjoying this 'extra' in-between time. The experience of an intimate relationship breakdown also provided an opportunity to re-evaluate existing relationships and to strengthen some of them, especially with parents and the friends who provided support.

Amongst our sample of mainly economically active, educated and childless young adults, the material consequences of intimate relationship breakdowns in young adulthood were more readily overcome than if they had happened in mid-life (Beer and Faulkner 2011), by which time couples have often moved to the suburbs and, in the presence of children, have adopted a gendered distribution of roles which renders women particularly vulnerable due to a (partial) withdrawal from the employment market (Hilton \& Anderson, 2009). Nevertheless, we noted that non-graduate participants had slightly more chaotic pathways. Whereas aspirations to achieve lasting relationships are found across all social backgrounds 
(Arnett, 2016), their actual achievement is indeed harder for less highly educated young adults. These young adults tend to come from less advantaged backgrounds than their more highly educated peers, with parents who have access to fewer resources to help them in case of need (Sirniö, Kauppinen and Martikainen 2017). This raises the issue of whether, for these young adults, the backwards and forwards movements we identified are actually a temporary life stage or a precursor to lasting housing pathways of instability. In this context, the crisis of the housing market in the UK (Bone and O'Reilly 2010) is an additional cause of concern for more vulnerable young adults. Therefore, further research should tackle the consequences of intimate relationship breakdown for non-graduates' housing pathways,

Although the relationship breakdowns of most of our participants may have fewer consequences for their future housing prospects than those experienced by older people, intimate relationship breakdowns linked to initial co-residence nonetheless proved to be critical life events, leading to a re-evaluation of their existing relationships and of their plans in relation to housing and family formation. It was especially emotionally draining and raised concerns about how to continue with their projects in order to still achieve a "successful" life script (Phoenix and Sparkes 2008). In addition, it is also important to highlight that because of the uncertainties weighing on their lives, family and career projects often conflicted. This is especially the case for educated young people who are highly invested in their career in the prospect of getting a well-paid job. When emerging adulthood is supposed to be the stage when young adults learn how to coordinate couple commitment with individual life plans (Shulman and Connolly 2013; Beck and Beck-Gernsheim 1995), it may also lead some of them to the conclusion that coordination is simply too difficult. In this context, access to homeownership may become harder even for young graduates, as two incomes are often required to secure a mortgage, whilst it may also be perceived as 'just too risky' given relationship instability. In conclusion, we are of the view that qualitative research is well suited to revealing the backwards and forwards movements associated with so-called 'intermediary' or 'transitional' housing arrangements linked to the 'in-between' phases of young adults' lives, as well as the more settled episodes in their housing pathways. These movements should also be taken into account through the greater availability of flexible but secure housing which will enable young people to foster lasting relationships and make plans for the future, whilst also allowing them to cope with the fall-out from unanticipated breakups. 


\section{Acknowledgements}

10

11

12

13

14

15

16

17

18

19

20

21

22

23

24

25

26

27

28

29

30

31

32

33

34

35

36

37

38

39

40

41

42

43

44

45

46

47

48

49

50

51

52

53

54

55

56

57

58

59

60 


\section{References}

[author(s)]

Amato, P. R. 2010. Research on Divorce: Continuing Trends and New Developments. Journal of Marriage and Family, 72(3): 650-666.

Antonucci, L., Hamilton, M., Roberts, S., eds. 2014. Young People and Social Policy in Europe Dealing with Risk, Inequality and Precarity in Times of Crisis. UK: Palgrave Macmillan.

Arnett, J. J. 2014. Emerging Adulthood: The Winding Road from the Late Teens through the Twenties, $2^{\text {nd }}$ Edition. Oxford: Oxford University Press.

Arnett, J. J. 2016. Does Emerging Adulthood Theory Apply Across Social Classes? National Data on a Persistent Question. Emerging Adulthood, 4(4), 227-235.

Arundel, R., and Ronald, R. 2016. Parental Co-residence, Shared Living and Emerging Adulthood in Europe: Semi-dependent Housing across Welfare Regime and Housing System Contexts, Journal of Youth Studies, 19(7): 885-905.

Beaujouan, É. and Ní Bhrolcháin, M. 2011. Cohabitation and marriage in Britain since the 1970s. Population Trends, 145.

Beer, A and Faulkner, D. 2011. Housing Transitions through the Life Course: Aspirations, Needs and Policy. Bristol: Policy Press.

Beck, U. and Beck-Gernscheim, E. 1995. The Normal Chaos of Love. Cambridge: Polity Press.

Berngruber, A. 2015. 'Generation Boomerang' in Germany? Returning to the Parental Home in Young Adulthood, Journal of Youth Studies, 18(10): 1274-1290.

Berrington, A. and Stone, J. 2014. Young Adults' Transitions to Residential Independence: The Role of Social and Housing Policy, in L. Antonucci, M. Hamilton and S. Roberts, S. (eds) Young People and Social Policy in Europe: Dealing with Risk, Inequality and Precarity in Times of Crisis. Basingstoke: Palgrave Macmillan.

Berrington, A., Perelli-Harris, B., and Trevena, P. 2015. Commitment and the Changing Sequence of Cohabitation, Childbearing, and Marriage: Insights from Qualitative Research in the UK, Demographic Research, 33(12): 327-362. 
Bone, J., and O’Reilly, K. 2010. No Place Called Home: The Causes and Social Consequences of the UK Housing 'Bubble', The British Journal of Sociology, 61(2): 231-55.

Buchmann, M., and Kriesi, I. (2011). The Transition to Adulthood in Europe. Annual Review of Sociology, 37, 481-503.

Brückner, H., and Mayer, K. U. (2005). De-standardization of the life course: What it might mean? And if it means anything, whether it actually took place? Advances in Life Course Research, 9, 27-53.

Bynner, J. 2001. British Youth Transitions in Comparative Perspective, Journal of Youth Studies, 4:1, 5-23.

Cohen, P., S. Kasen, H. Chen, C. Hartmark, and K. Gordon. 2003. Variations in Pattern of Developmental Transitions in the Emerging Adulthood Period. Developmental Psychology, 39(4): 657-669.

Forrest, R. and Yip, N. 2013. Young People and Housing: Transitions, Trajectories and Generational Fractures. London: Routledge.

Furlong, A., ed. 2016. Routledge Handbook of Youth and Young Adulthood, 2 ${ }^{\text {nd }}$ Edition. New York: Routledge.

Furlong, A., and Cartmel, F. 2006. Young People and Social Change: New Perspectives. Buckingham: Open University Press.

Hilton, J. M., and Anderson, T. L. 2009. Characteristics of women with children who divorce in midlife compared to those who remain married. Journal of Divorce \& Remarriage, 50(5), 309-329.

Isengard, B., König, R., and Szydlik, M. 2017. Money or Space?: Intergenerational Transfers in a Comparative Perspective, Housing Studies, 47(4): 1-23.

Jones, G. 1995. Leaving home. Buckingham: Open University Press.

Kalmijn, M., and Broese van Groenou, M. 2005. Differential Effects of Divorce on Social Integration, Journal of Social and Personal Relationships, 22(4): 455-476.

Lewis, J., West, A., Roberts, J., and Noden, P. 2016. The Experience of Co-residence: Young Adults Returning to the Parental Home after Graduation in England. Families, Relationships and Societies, 5(2): 247-262. 
Manning, W. E. D., and P. A. J. Smock. 2005. Measuring and Modeling Cohabitation: New Perspectives from Qualitative Data. Journal of Marriage and Family, 67 (4): 989 1002.

Ministry of Housing, Communities and Local Government (2018) English Housing Survey Headline Report 2016 to 2017, London: MHCLG. https://www.gov.uk/government/statistics/english-housing-survey-2016-to-2017headline-report

Mulder, C.H. 2007. The Family Context and Residential Choice: A Challenge for New Research, Population, Space and Place, 13(4): 265-278.

Neugarten, B.L., Moore, J.W. and Lowe, J.C. (1965). Age Norms, Age Constraints, and Adult Socialization. American Journal of Sociology, 70(6): 710-17.

ONS - Office for National Statistics, 2018a, Divorces in England and Wales, 2017, Available at

https://www.ons.gov.uk/peoplepopulationandcommunity/birthsdeathsandmarriages/di vorce/bulletins/divorcesinenglandandwales/2017

ONS - Office for National Statistics, 2018b, Births in England and Wales: 2017, Available at https://www.ons.gov.uk/peoplepopulationandcommunity/birthsdeathsandmarriages/li vebirths/bulletins/birthsummarytablesenglandandwales/2017

Panell, B. 2016. Home-Ownership or Bust? Commercial Research into Tenure Aspirations. London: Council for Mortgage Lenders.

Perelli-Harris, B., Mynarska, M., Berrington, A., Berghammer, C., Evans, A., Isupova, O., ...Vignoli, D. 2014. Towards a New Understanding of Cohabitation: Insights from Focus Group Research across Europe and Australia. Demographic Research, S17(34): 1043-1078.

Phoenix, C., and Sparkes, A.C. (2008). Athletic Bodies and Aging in Context: The Narrative Construction of Experienced and Anticipated Selves in Time. Journal of Aging Studies, 22: 211-21.

Rebughini, P. 2011. Friendship Dynamics between Emotions and Trials, Sociological Research Online, 16(1)3.

Roberts, J., Noden, P., West, A and Lewis, J. 2016. Living with the Parents: The Purpose of Young Graduates Return to the Parental Home in England, Journal of Youth Studies, 19(3): 319-337. 
Roberts, S. D. 2013. Youth Studies, Housing Transitions and the 'Missing Middle': Time for a Rethink? Sociological Research Online, 18(3).

Shulman, S., and J. Connolly. 2013. The Challenge of Romantic Relationships in Emerging Adulthood: A Review and Reconceptualization of the Field. Emerging Adulthood, 1 (1): 27-39.

Silva, J. M. 2016. High Hopes and Hidden Inequalities: How Social Class Shapes Pathways to Adulthood. Emerging Adulthood, 4(4), 239-241.

Sirniö, O., Kauppinen, T. M., Martikainen, P. 2017. Intergenerational determinants of joint labor market and family formation pathways in early adulthood, Advances in Life Course Research, 34: 10-21.

Stephens, M and Blenkinsopp, J. 2015. Young People and Social Security: An international Review. York: Joseph Rowntree Foundation. https://www.jrf.org.uk/report/young-people-and-social-security-international-review Stone, J., A. Berrington, and J. Falkingham. 2014. Gender, Turning Points, and Boomerangs: Returning Home in Young Adulthood in Great Britain. Demography, 51(1): 257-276.

Terhell, E. L., Broese van Groenou, M. I., and van Tilburg, T. 2007. Network Contact Changes in Early and Later Postseparation Years. Social Networks, 29(1): 1124.

Tuval-Mashiach, R., Hanson, J., and Shulman, S. 2015. Turning Points in the Romantic History of Emerging Adults, Journal of Youth Studies, 18(4): 434-450.

Wong, J. S. 2018. Toward a Theory of Gendered Projectivity and Linked Lives in the Transition to Adulthood, Journal of Family Theory \& Review, 10: 126-140. 
Table 1. Characteristics of the combined sample.

\begin{tabular}{|l|l|l|l|}
\hline & Northern England & Southern England & Total \\
\hline Participants' characteristics & & & \\
\hline Number of participants & 15 & 14 & 29 \\
\hline Number of female participants & 11 & 10 & 21 \\
\hline Mean age (range) & $30(23$ to 36$)$ & 30 (25 to 34) & 30 (mean) \\
\hline Experience of higher education & 15 & 11 & 26 \\
\hline Bachelor degree & 15 & 9 & 24 \\
\hline Grown up in the UK & 9 & 14 & 23 \\
\hline Relationship characteristics & & & 3 \\
\hline Married to former partner & 5 & 1 & 2 \\
\hline Engaged to former partner & 1 & $4.2(7$ mths to 10 yrs $)$ & 3.8 (mean) \\
\hline Mean duration (range) & $3.4(1$ to 6 yrs $)$ & 1 & 4 \\
\hline Same-sex relationships & 3 & & 8 \\
\hline
\end{tabular}


Table 1. Characteristics of the combined sample.

\begin{tabular}{|l|l|l|l|}
\hline & Northern England & Southern England & Total \\
\hline Participants' characteristics & & & \\
\hline Number of participants & 15 & 14 & 29 \\
\hline Number of female participants & 11 & 10 & 21 \\
\hline Mean age (range) & $30(23$ to 36$)$ & $30(25$ to 34$)$ & 30 (mean) \\
\hline Experience of higher education & 15 & 11 & 26 \\
\hline Bachelor degree & 15 & 9 & 24 \\
\hline Grown up in the UK & 9 & 14 & 23 \\
\hline Relationship characteristics & & & 8 \\
\hline Married to former partner & 5 & 3 & 2 \\
\hline Engaged to former partner & 1 & 1 & 3.8 (mean) \\
\hline Mean duration (range) & $3.4(1$ to 6 yrs) & $4.2(7$ mths to 10 yrs) & 4 \\
\hline Same-sex relationships & 3 & 1 & \\
\hline
\end{tabular}

